\title{
Exploring the Effective Counselling Practices being followed in India by Mental Health Professionals
}

\author{
Rasika Karkare ${ }^{1}$, Siddharth Dutt ${ }^{2}$ \\ ${ }^{1}$ Student in M.Sc. Counseling Psychology Course \\ ${ }^{2}$ Assistant Professor \\ ${ }^{1,2}$ Department of Psychology, Christ (Deemed to be University), Bangalore \\ Corresponding author: Rasika Karkare \\ Email: rasikakarkare633@gmail.com
}

\begin{abstract}
Background: Use of counselling as a therapeutic tool for the betterment of people in distress has grown rapidly over the years. As Mental Health professionals, dealing with humans and related psychological risks, it is one of the most responsible jobs. The current study is an attempt towards examining the effective counselling practices that are being followed in India and to gain an insight into the knowledge and training of Mental Health Counsellors.

Methods: The research was carried out on 14 counsellors working in Mumbai and Bangalore of minimum education qualification being a master's degree in counselling psychology. In this qualitative study, Sociodemographic data sheet, semi-structured interview schedule, and worksheet were used. The data gathered was analyzed by directed content analysis.

Results: Certain dimensions of counselling were in line with past literature, however, the need of licensure exam for counsellors, government body regulating policies and mental health laws, better coursework and practical training programs, difficulty in following complete ethical practices, emphasis on personal therapy and supervision emerged.

Conclusion: The current study provides rich data in terms of how effective the counselling practices are being followed in India and highlights the pitfalls and gaps which needs to be resolved.
\end{abstract}

Keywords: effective counselling practices, mental health counsellors, knowledge, and training, India.

(Paper received $-22^{\text {nd }}$ May 2018, Peer review completed $-20^{\text {th }}$ June 2019)

(Accepted $-25^{\text {th }}$ June 2019)

\section{INTRODUCTION}

Awareness of self, mindfulness, having the potential of thinking and feeling the emotions with clarity and comprehending them is a part and parcel of human life. Communicating and talking about the concerns has always been therapeutic for mankind [1]. Thus, the importance of interpersonal communication skills can never be underestimated in the caring professions [2]. Counselling is one of the helping professions which allows distressed people to communicate and deal with unmanageable feelings they have encountered in safe and confidential space. Counselling helps the person to understand their own reality and achieve an indepth understanding of self and others. Counselling as a helping profession reduces the demand on psychiatric services by limiting the less serious issues from escalating and by helping people to achieve and maintain the state of psychological wellbeing [3].

A counsellor being the key figure in therapeutic alliance must fulfil the requirements of effective counselling. Since there is no regulatory body or governing association to rule to the practice of counselling in India, it has unfortunately led to anyone without formal background and training, calling themselves a 'counsellor'. 
There seems to be a lot of unawareness, misinformation, and myths about counselling as a profession and what roles to expect from counsellors. Thus, the current study aims to develop in-depth understanding about the effective counselling practices followed by mental health counsellors in the Indian context, which will give a broader understanding about the current scenario and we are in a better position to discern the real situation.

\section{The Counsellor as a Therapeutic Person}

Multicultural sensitivity: Mental Health Counselling is a universal phenomenon and clients come to therapy from varied cultural backgrounds. Being aware of one's own culture, client's culture and personal biases is considered as the foundation to multicultural counselling competence. A literature study states that, only when the cultural context of the client is considered, counselling services will be consumer-driven. Most universities have programs which are inclusive of multicultural training in their curriculum. However, the existing information states that they remain ill-equipped to manage the cultural diversity of their clientele [4]. Clients and Counsellors are both products of their own cultural, personal and contextual factors which might have a dramatic impact on the counselling process and outcome.

Awareness of self: Self-awareness is one of the most important competency areas in the education and coursework of trainee counsellors [5]. Self-awareness is one of the valued concepts because it ensures continuous personal development. It is essential that the counsellor himself/herself attains a significant amount of psychological well-being and awareness in order to help the other person to do the same. A study mentioned, 'The counsellor can only take the client as far as they have been themselves'[6]. Another study cited that, self-reflection helps in building counselling competence by preventing violation in therapy, maintaining professional boundaries and providing a foundation for future mature professionalism [7].

Empathy: Empathy is a way of experiencing genuine respect, care, understanding client's situation by stepping into their shoes in a non-judgemental manner [8]. Carl Rogers in the year 1959, "Empathy is the ability to recognize and understand another person's internal private world, without losing the sense of separateness." Empathy helps clients to gain deeper self-understanding [9] and psychological healing [10] and therefore, empathy development is the major cornerstone in most counselling graduate training programs [11]. Research has also identified that people from collectivist culture were more accurately able to feel empathetic as compared to a person from individualistic culture [12]. A study found the level of empathy increased as the number of semesters passed by. However, they stress that empathy is a concept developed and emerged from western countries, so it is possible that we are looking at it from a distinct position [13].

Ethical codes of conduct and legal knowledge: Individuals in helping profession are in charge of creating good and not to harm client's, it is their obligation to act in an ethically consistent and sound manner [14]. Literature also stated having a continual upgrade in the knowledge of ethical codes of conduct and legal issues is essential for effective services. This training keeps counsellors updated with what the current scenario of the field is [15]. Effective counsellors work within the framework of five ethical principles which are beneficence, non-maleficence, autonomy, justice, fidelity [11].

Self-care and hardiness: Counselling is a human resource intensive job. Due to this intensity of emotions, Mental Health Counsellors are highly susceptible to burnout in their careers [16]. Hence, self-care is most important and is stressed as an ethical imperative in this profession since it acts as a buffer in burnout [1719]. The ethical codes in ACA also mentions self-care as a professional responsibility where counsellors should "engage in self-care activities to maintain and promote their own emotional, physical, mental, and spiritual well-being to best meet their professional responsibilities" (Section C, p. 8) A study stated that, other than self-care, there is a need to develop 'personal human qualities and abilities' which can act as buffer in burnout situations [20]. A study done cited Hardiness, as a promising buffer to reduce burnout, job dissatisfaction, and diminished well-being. Hardiness is defined as, "pattern of attitudes and skills that facilitates turning adversity into opportunity, thereby enhancing performance and health" [20].

Personal therapy and supervision: Seeking personal therapy is one of the most essential dimensions of selfcare. Literature revealed that more than $90 \%$ of mental health counsellors, reported satisfaction and positive outcomes in their own counselling experiences. [21]. It helps as the trainee counsellors get hands-on experience of how it feels to be on the other side of the chair, what are effective and ineffective behaviors 
of counsellors in the therapy session. It also helps in working on the stressors and unfinished businesses of the past which is important to deal with before trainees actually start providing counselling services. Also, in helping professions, having a skilled supervisor is an integral and mandated aspect of the profession. A study reported that those who received supervision felt supported and gained new perspectives and ideas for the cases [22]. Supervisors enable counsellors to adhere to professional, legal and ethical duties, assist them to develop skills, and support them with the emotional and psychological requirements of the working field [23].

The characteristics of effective counsellors have generated a lot of empirical research. However, the dimensions have been studied separately in relation to the counsellor's effectiveness. This study aims to gather an overview of all the dimensions of effective counselling practices together in the Indian context. The study will also explore the nature and quality of services being provided by the counsellors in India and gain insight into the knowledge base and training obtained by them. Effective Counselling Practices pertaining to this study mean, "The professional services mental health counsellors render to improve quality of their client's lives and bring about the positive change which will reflect through the knowledge of counselling skills and their application."

\section{Objectives of the Study}

- To study the nature and quality of work being provided to the clients by Counsellors.

- To gain insight into the knowledge and training of the Counsellors practicing in India.

\section{METHODOLOGY}

\section{Participants}

Participants of the study were 14 Mental Health Counsellors, who have earned a Master's degree in Counselling and specialized in Mental Health [24]. Data was collected from two Metropolitan cities i.e. Mumbai and Bangalore, 7 Mental Health Counsellors each. This study employed purposive sampling and snowball sampling. The inclusion criteria for participants were a minimum degree of Master's in counselling psychology, males and females, English speaking and minimum a year of counselling experience. Exclusion criteria were, just a graduate degree in psychology and non-psychology background.

\section{Design}

The study adopted a Qualitative method of research. The primary data collection method was semistructured interviews containing open-ended questions to gain elaborate information. Researcher aimed to gain an in-depth understanding of Counselling practices being carried out in the Indian context and their effectiveness. For the same, Exploratory Research Design was suitable. Researcher gained a better understanding of the problem with varying levels of depth. Exploratory research forms the basis for more conclusive research by laying the foundation of a groundwork.

\section{Instruments used}

Researcher created a pool of questions pertaining to all dimensions and final set of questions were derived by doing detailed analysis keeping in mind the cultural context and open-ended nature of questions to get elaborate information under guide's supervision. The questionnaire was validated by 2 professors who are working with mental health counsellors. Member check was done to assess the feasibility, validity, accuracy of words, the credibility of questions etc. Researcher used this semi-structured interview to gain the information from the primary sources of the data, i.e. Counsellors. An informed consent form, Sociodemographic data sheet, interview schedule with 18 questions, one worksheet and sample debriefing sheet has been attached in the appendix.

The proposal was presented to internal and external supervisor for evaluation and the proposal received ethics clearance from the committee.

Pilot Phase: In this study, the researcher conducted a semi-structured interview with one mental health counsellor to understand how the flow of questions was able to generalize information, how much time did 
it take to complete the interview, whether the wording of open-ended questions was effective to etc. This interview was later included in the main sample as there was no need for further modification.

Main Phase: The researcher collected the data from two urban cities, viz Bangalore and Mumbai. Researcher met them face to face in a conducive setting to carry out the interview. They began with given informed consent form, in which details of the study, information about the researcher and few ethical considerations will be mentioned. Once the participant signed the informed consent form, demographic details sheet was given to fill up, then the questions were asked mentioned in the schedule. Responses were noted down immediately in their verbatim by the researcher. Every interview approximately took an hour.

\section{STATISTICAL ANALYSIS}

This research study adopted content analysis to analyse the data gathered. It is a method where, manifest and latent content of a communicated material, in this study, interview transcribes, are analyzed through classification, developing of a coding system and identifying themes fitting into the codes developed. Content analysis is defined as a research technique for making replicable and valid inferences from data to their context [25]. Thus, if one examines the definitions carefully, this method is all about objectivity, context, validity, and replicability.

\section{RESULTS}

All the 14 participants were Indian, belonging to varied cultural backgrounds like Christian, Muslim, Parsi, and Hindu. Common employment setting in all the participants was private practice, however, they worked at various other settings.

Table 1: Socio demographic details of the mental health counsellors in India ( $n=14)$

\begin{tabular}{|l|l|}
\hline Variables & $\begin{array}{l}\text { Number of } \\
\text { participants (n=14) }\end{array}$ \\
\hline Gender & 2 \\
\hline Males & 12 \\
\hline Females & \multicolumn{2}{|l|}{} \\
\hline Education Qualification & 12 \\
\hline M.Sc. in counselling Psychology & 1 \\
\hline M.Sc. and M.Phil. & (28-65 years) \\
\hline M.A. and PhD. & (37 years) \\
\hline Overall Age Range & $100-250$ hours \\
\hline Overall Mean Age & \\
\hline Supervised Working Hours &
\end{tabular}

While exploring the meaning of counselling through participants' understanding, three distinct themes were emerged, and participants responded in various combinations between these three. 10 of them explained it as helping people in need, eight of them believed that it is giving clients the sense of right direction and nine said that it is working towards better versions of the clients to enable more fulfilling lives. Counsellor Z.M. mentioned, "It's the process where you help the people in need, give them right direction, aid them in helping themselves and leading them to more fulfilling lives." Counselling process was further explored in relation with various dimensions.

\section{Multicultural Understanding}

When asked about how to deal with clients from different cultural backgrounds, all participants stressed the importance of having the multicultural understanding and being updated about various cultural practices and norms. Four participants mentioned multicultural understanding comes with growing years of 
experience, nine participants believed that reading about cultures helps, while eight of them stated that being honest is the key and openly asking the clients questions about their culture and getting to know through interactive conversations is the best way. Counsellor T.K. said, "I ask clients verbally, it also helps in rapport building. Sometimes I do google and read the things I don't know. Honesty is the key. Accept, acknowledge and be updated."

\section{Mental Health Laws and Clients Rights}

All participants emphasized the importance of laws and rights of clients for their safety in the counselling process. However, six participants mentioned there is confusion and laws are not clearly stated. nine of them mentioned, despite prescribed laws and rights, enforcement is the major issue in India. 12 participants, i.e. $85 \%$ of them reported the great felt need of the having licensure exams for counsellors, government body or authority to ensure the enforcement of laws and policies. Counsellor B.S. mentioned,

"There are a lot of grey areas when it comes to legality and rights in the mental health profession. We all are confused. We know clients rights or acts like POCSO, but we don't know how firm they are, how strong the implication they hold. There really is a need for authority, committee, exams, government bodies in India regarding mental health."

\section{Preferred Counselling Style}

When asked about the counselling style they have or whether they take an active/passive role, nine participants reported taking a client-centred approach to counselling where they let the clients take charge. Counsellor E.M said, "I usually take the back seat. I observe clients in the therapy, their nonverbal cues, let them formulate their own goals. I only aid the entire process. After all, they know themselves the best." Four participants mentioned taking a directive stance and giving clients the right directions. Counsellor S.A. stated, "I take a directive stand. I follow CBT, so when it comes to thought disputing, clients require a directive push. Sometimes they are clueless, and you need to push them forward." Two participants reported taking either directive or passive role depending on the theory and interventions being used.

\section{Transference and Countertransference}

About dealing with transference, five participants mentioned rarely coming across such cases. Six of them mentioned if transference is observed, bringing it to the client's notice and openly talking about it. One participant mentioned, transference being productive for the therapy. Counsellor S.P. said, "Transference is good for the process because it helps me getting to know the client better and can express their feelings to me." Only six participants reported working on countertransference in personal therapy and supervision or talking about it with colleagues.

\section{Burn Out and Self-Care}

$35 \%$ reported they have never faced burn out so far in the profession, $58 \%$ reported not having faced burn out, but have experienced phases of boredom, stagnation or monotonous work. Only one participant i.e. $7 \%$, R.M. reported having faced burn out in the practice said,

"Yes when I was going through personal and family issues, I used to be so fatigued. I was going through physical problems too. That year was not great for me. I kept on working, but it wasn't a great practice."

All participants mentioned the need for self-care in counselling, by engaging in hobbies, doing meditation, socializing and $35 \%$ of them distinctly reported personal therapy as a major part of self-care. Counsellor E.M. said, "We need to be better ourselves to take care of others. This profession demands a lot from you. It's mentally exhausting. So, to keep myself at peace, I take proper sleep, enjoy my hobbies, listen to music, enjoy family time and go for regular personal therapy."

\section{Personal Therapy and Supervision}

Seven participants reported going for regular personal therapy and one participant reported have gone for four years but now have discontinued going. $42 \%$ of participants mentioned that they have never been for personal therapy. Six participants mentioned seeking monthly supervision sessions, however, eight of them 
mentioned they have never attended formal supervision. Four out of these eight stated they have a group of co-workers and counsellors working around, with whom they discuss the cases and resolve difficulties.

\section{Empathetic Understanding and Neutrality}

All participants stated empathy being the most essential skill, which is the crux of the therapy. The empathetic approach towards clients, stepping into their shoes enables counsellors to understand the client's perspective and clients feel understood and heard as well. It is an essential tool to develop rapport and deal with resistance. When asked about expressing empathy, four of them mentioned through verbal sentences like "I understand", "It must be very difficult for you" etc, Two of them mentioned through physical touch like gently patting back or touching hand etc, Three of them mentioned through body language like, leaning forward, making eye contact etc, and five of them mentioned the combination of all three is the best way to express empathy. All participants had an insight that, along with having empathy for clients, maintaining neutrality is important to avoid personal judgments and biases. However, nine participants responded having difficulty in holding back the judgments. Counsellor E.M stated, "I know objectivity is important, but when I have strong opinions, I struggle to understand the client's perspective." Four female counsellors reported siding with their female clients.

\section{Contracting and Termination}

When participants were asked how do they begin the session, eight participants mentioned taking oral consent from participants, five participants mentioned taking a written consent. These 13 participants, in addition, mentioned explaining the rights of clients, the process of therapy, fees charges etc orally. However, one participant mentioned having a website, where clients can read everything beforehand and book a preferred slot, so when the client comes in for therapy, they are well-informed ad therapy can be started. When asked about termination, 12 participants mentioned, it happens in the flow of the sessions. Out of these 12 , four stated, clearly mentioning an approximate number of sessions required at the beginning. Five of them said, as the therapy progresses, clients themselves understand the progress they are making, and they ask for terminating the therapy. Other three mentioned talking about termination on a regular basis, more towards the end of therapy, telling them they're capable enough to function without therapy. However, other than these 12, two participants mentioned, termination doesn't need any preparation. According to counsellor T.K,

"I don't stress much on it. It generates anxiety. I take sessions with their pace and let them decide how long they want to come in therapy. The journey is more important than the destination. If the journey is smooth, reaching the destination will not create anxiety."

\section{Research Orientation}

All except two, i.e. $85 \%$ of participants mentioned understanding the importance of research, but not being research oriented. As counsellors they believe in using evidence-based interventions, however, they do not conduct research themselves. The reasons they mentioned were lack of time, not having an inclination towards research, lack of aptitude for research and already existing research base. Counsellor B.S said, "I am personally not very research oriented. I don't let that be the main factor in my therapy. And anyway, who has so much time? It's a long commitment." However, the other two, i.e. 15\% stated they enjoy conducting research, writing papers to keep themselves well-read and basing their practice on evidence.

\section{Ethics and Professionalism}

All participants mentioned ethics and professionalism being the crux of the therapy. They mentioned the client's rights and ethics in therapy make clients feel safe and secured. They are also important to maintain the well-being and safety of counsellors. It ensures a standard of good counselling practice. However, nine participants mentioned even though they are so important, no one really follows them. Following complete ethical practices is not possible today. Counsellor B.S. Mentioned,

"Yes, they are important to follow but no one follows it in its purest sense. There's no qualification also, so anyone comes and does counselling from any background. Following all ethical aspects is difficult, especially dual relationship." 


\section{Counselling Skills}

Participants were asked to name a few skills required in the counselling process. Seven participant's responses included providing direction, giving insights, making them functionally independent, trust generation, good communication, lending helping hands etc. They were also given a worksheet to fill which included, a name of the counselling skill and for the same, they had to write their understanding of the skill when that skill is likely to be used and the predicted outcome of using the skill. It was observed that all participants mentioned reframing and paraphrasing being the same skill. Nine out of 12 participants mentioned they do not use confrontation.

\section{DISCUSSION}

The results revealed counsellors' understanding of the 'counselling' which was in line with the first definition given by The British Association for Counselling (BAC), now the BACP, "Counselling is the skilled and principled use of relationship to facilitate self- knowledge, emotional acceptance and growth and the optimal development of personal resources. The overall aim is to provide an opportunity to work towards living more satisfyingly and resourcefully".

The current study revealed counsellors believe Multicultural understanding being the important aspect of counselling practices. Cultural, personal, contextual, and universal factors integrate to form the personal cultural identities of both the counsellor and the client. These personal cultural identities may have a dramatic impact on the success of the counselling process and must be considered in both theory and practice [4]. Results revealed Mental health laws and policies being the topic of debate among professionals. Majority of the participants reporting the confusion regarding laws, unsure impacts of policies, strictness of enforcement, no licensure exams for becoming a mental health counsellor, no government body to regulate the laws and rights, are the reasons for dropping down the standards of the counselling profession.

Being aware of self is a basic cornerstone for the development of the professional self, which is important of a matured professional. Counsellor do need guidance in becoming aware of how their own feelings, attitudes, and relationships with clients are major factors in the helping process [7]. However, Current study revealed less than $50 \%$ reported taking supervision and guidance from colleagues. Transference or countertransference, if left unaddressed, or worse, unrecognized, can be detrimental for the therapy.

Even though the counsellor's job is high on satisfaction and that of meaningful noble work, they tend to go through burnout which affects their professional quality of life. The only participant that experienced burnout, continued working with her clients, which is worrisome as it may have produced adverse effects on clients. Only $35 \%$ of participants reported going for personal therapy and supervision which are great contributors to deal with burnout. The importance of personal therapy and supervision should be emphasized in the coursework and should be made mandate as a part of practical training to deal with this problem. To build empathy as a skill and to maintain neutrality towards clients, personal therapy again plays a significant role. The 4 female participants mentioning being partial towards female clients, do not seek personal therapy.

In therapy, it is essential to obtain signatures on the informed consent form, so that counsellors have physical proof which also protects clients and professional's wellbeing. The current study emphasized few participants take informed consent, leaving others in not so safe professional workspace. Majority of participants mentioned termination happens inflow of therapy when the client is competent enough. How therapy ends has important implications for the clients. As this study revealed, addressing endings from the beginning, and on an ongoing basis throughout treatment, can help ensure that treatment is provided and ended in an ethical and clinically competent manner.

Counsellors knowing the impact of evidence-based practice however, they do not engage in conducting research. Psychologists should engage in ongoing professional development by keeping themselves up to date by research and contributing to the field. It also keeps them well read and updated about the advances in the field. Current study findings do not go in line with the above as only 2 participants reported conducting research. The ethical code of conduct being the heart of counselling, familiarity with ethical guidelines is paramount. Ethical competence is developed over time with experience as a beginner, 
competent, proficient and an expert. The current study revealed, following counselling practice in the purest form is not possible, especially the dual relationship. In the Parsi communities, where the population is very less, it is difficult to avoid a dual relationship. This also highlights the lack of cultural sensitivity, where clients from a particular community are not willing to go to counsellors of a different community. Counsellors can psycho educate the clients, make them open to seek help from another counsellor, and refer them to someone. Counsellors do not have a conducive environment and society to practice ethical counselling practices, which is harmful to clients.

Developing and thorough training in counselling micro skills is what distinguishes a professional counsellor from a layman giving advice and guidance. They are the essential tools which help in bringing out the best in client and facilitating therapy [9]. Counselling micro skills are active listening, nonverbal observation, Questioning, Empathy, Rapport building, reflection of feeling, reflection of meaning, paraphrasing, summarising, reframing, self-disclosure and confrontation. However, the participants responded with processes happening in therapy like insight generation, direction seeking, making clients functionally dependent etc, which happens with the use of micro skills. Worksheet revealed that counsellors lack understanding of technical terms and concepts and differences between two skills. Post the training, through years of practice, they should keep themselves well-read and updated with the terms and language of the field. Everyone denied using confrontation, which is an important skill in breaking the stuck point of clients. The current study provides rich data in terms of how effective the counselling practices are being followed in India and highlights the pitfalls which need to be resolved. Counselling is a profession with responsibility and hence should be practiced with dignity and keeping in mind the safety and integrity of clients.

\section{CONCLUSION}

The implications for this study are for working mental health counsellors, who can learn about the gaps in effective counselling practices and current status of the filed to bridge those gaps. This study can provide a knowledge base for trainee counsellors to avoid maladaptive practices and adhere to effective ones. Since efficient counsellors are shaped through effective coursework and practical based training, institutes need to investigate their courses and upgrade them time to time as per the need. It will also be beneficial on the government level, to make strict enforcement of laws and rights for clients, minimum education qualification and psychology background, having licensure exam for counsellors to ensure the standard of the profession and contribute positively in the society.

\section{REFERENCES}

1. Mallett J, Dougherty L, editors. The Royal Marsden Hospital manual of clinical nursing procedures. Blackwell Science; 2000.

2. Chauhan G, Long A. Communication is the essence of nursing care 1: breaking bad news. Br J Nurs 2000;9(14):931-8.

3. Arthur N. Counsellor Education for Developing Multicultural Counselling Competencies.

4. Arthur N, Russell-Mayhew S. Preparing counsellors for interprofessional collaboration through supervision and lateral mentoring. Canadian Journal of Counselling and Psychotherapy/Revue canadienne de counseling et de psychothérapie 2010;44(3).

5. Uhlemann MR, Jordan D. Self awareness and the effective counsellor: A framework for assessment. Can J Couns Psychother 1981;15(2):30-45.

6. Sinason V. In defence of therapy for training. Controversies in Psychotherapy and Counselling 1999;12:155.

7. Urdang E. Awareness of self-A critical tool. Soc Work Educ 2010;29(5):523-38.

8. Norcross JC. Psychotherapist self-care: Practitioner-tested, research-informed strategies. Profess Psychol Res Pract 2000;31(6):710-7.

9. Kaelber KA, Schwartz RC. Empathy and emotional intelligence among Eastern and Western counsellor trainees: A preliminary study. Int J Adv Couns 2014;36(3):274-86.

10. Sinclair SL, Monk G. Discursive empathy: A new foundation for therapeutic practice. Br J Guid Couns 2005;33(3):333-49.

11. Russell-Chapin LA, Ivey AE. Your supervised practicum and internship. Belmont, CA: Thomson Brooks/Cole. 2004. 
12. Kitchener KS. Intuition, critical evaluation and ethical principles: The foundation for ethical decisions in counseling psychology. The Couns Psychol 1984;12(3):43-55.

13. Sori CF, Hecker LL. Ethical and legal considerations when counseling children and families. Engaging children in family therapy: Creative approaches to integrating theory and research in clinical practice. 2006 Pp. 159-74.

14. Lawson G. Counselor wellness and impairment: A national survey. J Human Couns Educ Dev 2007;46(1):2034.

15. Collins S, Long A. Too tired to care? The psychological effects of working with trauma. J Psychiatr Ment Health Nurs 2003;10(1):17-27.

16. Kraus VI. Relationship Between Self-Care and Compassion Satisfaction, Compassion Fatigue, and Burnout Among Mental Health Professionals Working with Adolescent Sex Offenders. Couns Clin Psychol J 2005;2(2).

17. Figley CR. Measuring compassion satisfaction as well as fatigue: Developmental history of the compassion satisfaction and fatigue test. In Treating compassion fatigue 2013 May 13 (pp. 115-128). Routledge.

18. Morse G, Salyers MP, Rollins AL, Monroe-DeVita M, Pfahler C. Burnout in mental health services: A review of the problem and its remediation. Adm Policy Ment Health Ment Health Serv Res 2012;39(5):341-52.

19. Ramirez AJ, Graham J, Richards MA, Gregory WM, Cull A. Mental health of hospital consultants: the effects of stress and satisfaction at work. Lancet 1996;347(9003):724-8.

20. Orlinsky DE, Rønnestad MH. How psychotherapists develop: A study of therapeutic work and professional growth. American Psychological Association; 2005.

21. Patton $\mathrm{W}, \mathrm{McMahon} \mathrm{M}$. Theoretical and practical perspectives for the future of educational and vocational guidance in Australia. Int J Educ Vocat Guid 2002;2(1):39-49.

22. Stebnicki MA. Disaster mental health counseling: Responding to trauma in a multicultural context. Springer Publishing Company; 2016.

23. Krippendorff K. Content analysis: An introduction to its methodology. Sage publications; 2018.

\author{
$* * * * * * * * * * * * * * * * * * * * * * * * * * * * * * * * * * * *$ \\ Acknowledgements - Nil \\ Conflict of Interest - Nil \\ Funding - Nil
}

